\title{
PERFORMANCE EVALUATION OF TWO SYSTEMS FOR MIXING AND PROCESSING FEED ADDITIVES AND CONCENTRATES
}

Morad, M. M. ${ }^{1}$

\author{
M. M. A. El-Sharabasy ${ }^{2}$
}

S.M. Abdel-Samie ${ }^{3}$

\section{ABSTRACT}

The main experiments were carried out in a local factory for manufacturing feed additives and concentrates in El-Obour city, Kalubia Governorate to study the effect of some operating parameters on the performance of two mixing units. Experiments were carried out using both big mixer (Buhler) and small mixer (Ribbon) under four different batch sizes, four different mixing times and three different carrier materials. Evaluation of the performance of both mixers was carried out taking into consideration the mixer productivity, homogeneity, coefficient of variation, consumed energy and mixing cost. The obtained results reveal t the following: The big mixer is recommended to be used under the following conditions: (Batch size of between 1000 and $1200 \mathrm{~kg}$; mixing time of between 10 and $15 \mathrm{~min}$, and carrier materials of calcium carbonate and corn gluten with ratio of 3:1). The small mixer is recommended to be used under the following conditions: (Batch size of between 200 and $250 \mathrm{~kg}$; mixing time of between 40 and 60 min, and carrier materials of Maltodextrin and sucrose with ratio of 1:1).

\section{INTRODUCTION}

$\mathrm{M}$ anufacture of mixing unit for feed additives means at first homogeneous mixing of extremely small parts of additives (micro components) into large quantities of feed mixture components. The objective of the mixing process is to produce feed additives in which nutrients and medication are uniformity distributed and well mixed. Therefore, mixing is one of the essential technological processes for production of compound feed additives for animals and it has important influence on the quality of the final product.

\footnotetext{
${ }^{1}$ Professor of Agric. Eng., Fac. of Agric., Zagazig Univ., Egypt. ${ }^{2}$ Assist. Prof. of Agric. Eng., Fac. of Agric., Zagazig Univ., Egypt. ${ }^{3}$ Graduate student, Agric. Eng., Fac. of Agric., Zagazig Univ., Egypt.
} 
Feed additives are a substance added to feed in micro quantities to fulfill specific nutritional need essential nutrients in the form of amino acids, vitamins, and minerals. The problems are the addition and homogeneous distribution of the micro components (additives), the stability of this final mixture and the avoidance of concentration losses and carry-over of the additives in the total production of plant. The mixing technology will be evaluated by the so-called working accuracy of the production unit, which is different from the mixing efficiency of the mixer. This efficiency of the mixer will be expressed by the homogeneity obtained after different or usual mixing times for the used mixer and material composition. The homogeneity of the mixture after the usual mixing time and after conveying the mixture to the final stations expressed by the coefficient of variation. Dirksen et al. (1980) mentioned that on-farm feed systems normally use three types of mixers: vertical, horizontal, or rotating drum. Vertical mixers take up the least floor space and have the greatest height requirement. Mixing times on vertical mixers normally run 10 to $15 \mathrm{~min}$. Horizontal and rotating drum mixers can mix in 5 to 10 min either type will do a satisfactory mixing job for farm use. The vertical mixer is composed of an upright tank, usually round, with a vertical auger in the center to mix the feed. Smaller, less costly mixers are usually of the vertical type. Typical vertical mixers are available in models ranging in size from a 1/2-ton model requiring a 3-horsepower motor up to a 4-ton model requiring a 25 -horsepower motor. Larger mixers are usually of the horizontal type with a horizontal shaft in the center carrying paddles or ribbons for the mixing. Power requirements range from 3 to 5 horsepower for an 1/2-ton mixer up to 20 to 30 horsepower for a 3-ton model. ASAE (1997a, b) identified a number of methods of on-farm feed mixing which are available to livestock farmers. Mixer wagons (mobile equipment for producing complete diet feeds or " total mixed rations" are more likely to be used on mixed arable and livestock farms or farms that grow a number of different grass crops, rather than all-grass farms. Traylor (1997) mentioned that increasing mixing time from 0 to 0.5 min decreased the $\mathrm{CV}$ for $\mathrm{Cr}$ (chromic oxide was the marker used in this experiment) concentration from 10.7 to $28 \%$ Diet uniformity was improved further as mixing time was increased to $4 \mathrm{~min}$ (CV of 12\%). Rate and efficiency of gain increased markedly as mixing time was increased from 0 to $0.5 \mathrm{~min}$, with little response to increasing mixing time further to $4 \mathrm{~min}$. Clark and Behnke (2006) reported that utilizing a common corn-soybean meal based 
poultry diet, as mixing time increased there was an overall decrease in percentage coefficient of variation (CV) observed which was independent of which marker was used. Crude protein should be considered to be marker as several ingredients in the batch contribute some level of protein and overall decreased numerically less than $1 \% \mathrm{CV}$. To evaluate the effects of feed uniformity on broiler performance, as determined by $\mathrm{CV}$, methionine was added to a basal diet and mixed for 10, 20, 30, 40, or 120-s, with methionine being the only ingredient varying. Portillo et al. (2007) looked at a wide range of parameters that influence blending in a bladed mixer. They report that mixing improves with decreasing rotation rate even though powder is subjected to greater shear forces at larger rotation rates. They hypothesize that the reduced mixing at higher rotational speeds is due to turboelectric effects. Surface charges developed by greater stirring and shaking, and hence increased turbo charging, lead to the formation of powder deposits within the mixer which degrade output homogeneity. Avik and Wassgrena (2009) investigated the influence of fill level and impeller rotation rate in a horizontal bladed continuous mixer. Particle flow within the mixer was found to be strongly dependent on the impeller rotation rate and fill level. The axial flow rates showed significant variation with impeller rotation rate and fill, and also showed considerable variation over the course of a shaft revolution. Favorable mixing was obtained at smaller impeller rotation rates for larger fills, but at larger impeller rotation rates for smaller fills. So, the objectives of this study are: evaluating the performance of two systems for mixing and processing feed additives and concentrates. Optimizing some operating parameters affecting the performance of the used mixers (mixing time, carrier material and batch size). Measuring the energy requirements for operating the used mixers. Comparing the used mixers from the economic point of view.

\section{MATERIALS AND METHOD}

\subsection{MATERIALS:}

2.1.1. Experimental ration: the experimental ration for BUHLER (big mixer) is tabulated in table (1), while the experimental ration for RIBBON (small mixer) is tabulated in table (2).

Table (1): Experimental ration for big mixer (BUHLER) using corn gluten and calcium carbonate as a carrier materials.

\begin{tabular}{ccccc}
\hline \multirow{2}{*}{ Composition } & \multicolumn{4}{c}{ Batch size, $(\mathbf{k g})$} \\
\cline { 2 - 5 } & 600 & 800 & 1000 & 1200 \\
\hline
\end{tabular}




\begin{tabular}{|c|c|c|c|c|}
\hline Vitamin A 500,000 I.U/mg, (kg) & 12 & 16 & 20 & 24 \\
\hline Vitamin D3 500,000 I.U/mg, (kg) & 2.4 & 3.2 & 4 & 4.8 \\
\hline Vitamin E $50 \%,(\mathrm{~kg})$ & 2.4 & 3.2 & 4 & 4.8 \\
\hline Corn gluten, $(\mathrm{kg})$ & 241 & 320 & 400 & 480 \\
\hline Calcium carbonate, $(\mathrm{kg})$ & 342.2 & 457.6 & 572 & 686.4 \\
\hline \multicolumn{5}{|c|}{$\begin{array}{l}\text { Table (2): Experimental ration for small mixer (RIBBON) using } \\
\text { Maltodextrin and sucrose as a carrier materials. }\end{array}$} \\
\hline \multirow{2}{*}{ Composition } & \multicolumn{4}{|c|}{ Batch size, $(\mathrm{kg})$} \\
\hline & 100 & 150 & 200 & 250 \\
\hline Nicotinamide F.G, $(\mathrm{kg})$ & 0.2 & 3 & 4 & 5 \\
\hline Aerosil 200, (kg) & 2 & 0.15 & 0.2 & 0.25 \\
\hline Vitamin $(\mathrm{K} 3)$ minadion, $(\mathrm{kg})$ & 0.1 & 0.6 & 0.8 & 1 \\
\hline Vitamin (B12) $1 \%,(\mathrm{~kg})$ & 1 & 1.5 & 2 & 2.5 \\
\hline Folic acid, (kg) & 0.025 & 0.037 & 0.05 & 0.062 \\
\hline Vitamin B6 (pyridoxine) HCL, (kg) & 0.2 & 0.3 & 0.4 & 0.5 \\
\hline Vitamin B2 $80 \%,(\mathrm{~kg})$ & 0.5 & 0.75 & 1 & 1.25 \\
\hline Vitamin B, (kg) & 0.2 & 0.3 & 0.4 & 0.5 \\
\hline Cal. pantothenate, $(\mathrm{kg})$ & 0.4 & 0.6 & 0.8 & 1 \\
\hline Maltodextrin, (kg) & 47.889 & 71.513 & 95.35 & 119.188 \\
\hline Sucrose, $(\mathrm{kg})$ & 47.486 & 71.25 & 95 & 118.75 \\
\hline
\end{tabular}

2.1.2. Mixing units: two mixing units called (BUHLER) big mixer and (RIBBON) small mixer were used. Both mixers consist of the following main parts: feeding hopper, feeding screw, mixing body, output gate, electric motor with output power of $30 \mathrm{~kW}$ at $500 \mathrm{rpm}$ for big mixer and electric motor with output power of $11 \mathrm{~kW}$ at $1480 \mathrm{rpm}$ for the small mixer.

\subsection{METHOD:}

The main experiments were carried out in a local factory in El- Obour city, Cairo, Egypt to study the effect of some operating and engineering parameters on the performance of two mixing units.

2.2.1. Experimental conditions: the two mixing units were examined as a function of change in the following parameters:

- Batch size: 600, 800, 1000 and $1200 \mathrm{~kg}$ for the BUHLER (big mixer). And 100, 150, 200, and $250 \mathrm{~kg}$ for the RIBBON (small mixer).

- Mixing times: 5, 10, 15 and $20 \mathrm{~min}$ for BUHLER (big mixer). And 30, 40, 50 and 60 min for RIBBON (small mixer). 
- Carrier materials: Corn gluten and calcium carbonate, calcium carbonate only and corn gluten only for BUHLER (big mixer). And Maltodextrin and sucrose, Maltodextrin only and Sucrose only for RIBBON (small mixer).

2.2.2. Performance indicators: The performance of the two mixers was evaluated taking into consideration the following indicators:

- The mean: The mean is the average value of a population. It can be calculated as follows:

$$
\bar{X}=\frac{\sum x i}{n}
$$

Where: The mean $(X)=$ the average value of a population, defined by procedure. $\quad \Sigma x i=$ Sum of samples. $\quad n=$ Number of samples assayed.

- Coefficient of variation (C.V.): An expression for sample variability relative to the mean. It is defined as follows:

$$
\text { C.V. }=\frac{S}{\bar{X}} \times 100, \%
$$

Where: $S=$ Standard deviation. The amount of variation in the sample population defined as follows:

$$
S=\sqrt{\frac{\sum x^{2}-\frac{\left(\sum x i\right)^{2}}{n}}{n-1}}
$$

The coefficient of variation under (10\%) is considered excellent, of between $10-15 \%$ is considered good, of between $15-20 \%$ is considered fair, while with value more than $20 \%$ is considered poor, as reported by (Coates and Tanaka, 1992).

- Homogeneity: Sufficient samples were taken from the top, middle and bottom of the mixer. Homogeneity is calculated by determining both maximum and minimum assay, then calculating the deviation between maximum assay and mean and also between minimum assay and mean then the greater value is divided by mean and multiplying by 100 . It can be also explained as following:

1. Determine maximum assay.

2. Determine minimum assay.

3. Deviation between maximum and mean.

4. Deviation between minimum and mean.

$$
\text { Homogeneity }=\frac{\text { The greater of step }(3) \text { or }(4)}{\text { Mean }} \times 100
$$


- Energy requirements: The energy requirements were obtained using the following equation:

$$
\text { Energy requirements }=\frac{\text { Power },(k W)}{\text { Mixer productivity, }(\mathrm{Mg} / \mathrm{h})},(\mathrm{kW} \cdot \mathrm{h} / \mathrm{Mg})
$$

- Mixer productivity: It was calculated from the following relation:

$$
\text { Mixer productivity }=\frac{W_{P}}{T} \times 3.6,(\mathrm{~kg} / \mathrm{h})
$$

Where: $\quad W_{p}$ : Mixed mass, $(\mathrm{kg}) . \quad T$ : Consumed time, $(\mathrm{s})$.

- Mixing cost: The mixer hourly cost is estimated according to the conventional method of estimating both fixed and variable costs. While mixing cost was calculated using the following formula:

$$
\text { Mixing } \cos t=\frac{\text { Mixer hourly } \cos t,(L . E / h)}{\text { Mixer productivity, }(M g / h)}, L . E / M g
$$

\section{RESULTS AND DISCUSSION}

The discussion will cover the obtained results under the following heads:

\subsection{BUHLER (Big mixer):}

\subsubsection{Effect of mixing time and batch size on the mixer performance using corn gluten and calcium carbonate as a carrier material:}

Concerning the effect of mixing time on mixer performance at batch size of $600 \mathrm{~kg}$, Results in Fig. (1) show that increasing mixing time from 5 to 10 min decreased both C.V. values from 21.85 to $7.70 \%$ and homogeneity from 24.77 to $14.47 \%$, and also increased the mean from 18.82to 20.88. Any further increase in mixing time more than $10 \mathrm{~min}$ up to $20 \mathrm{~min}$, the C.V. values and homogeneity will increase. Relating to the effect of mixing time on mixer performance at batch size of $800 \mathrm{~kg}$, results show that increasing mixing time from 5 to $15 \mathrm{~min}$ decreased both C.V. values from 12.04 to $4.48 \%$, homogeneity from 18.33 to $7.12 \%$ and the mean from 20.96 to 20.68 . Any further increase in mixing time more than 15 min up to $20 \mathrm{~min}$, the C.V. values will increase from 4.84 to $13.79 \%$, also homogeneity will increase from 7.12 to $19.06 \%$, while the mean will decrease from 20.68 to 20.06 . With regard to the effect of mixing time on mixer performance at batch size of $1000 \mathrm{~kg}$, results show that increasing mixing time from 5 to $15 \mathrm{~min}$ decreased both C.V. values from 18.88 to $6.23 \%$, homogeneity from 27.90 to $8.45 \%$ and the mean from 20.70 to 20.27. Any further increase in mixing time more than $15 \mathrm{~min}$ up to $20 \mathrm{~min}$, the C.V. values will increase from 6.23 to $11.07 \%$, also homogeneity will 
increase from 8.45 to $11.75 \%$, while the mean will decrease from 20.27 to 20.17. As to the effect of mixing time on mixer performance at batch size of $1200 \mathrm{~kg}$, results show that increasing mixing time from 5 to $10 \mathrm{~min}$ decreased both C.V. values from 9.75 to $5.21 \%$ and homogeneity from 12.48 to $6.86 \%$, while increased the mean from 19.45 to 20.25 . Any further increase in mixing time more than $10 \mathrm{~min}$ up to $20 \mathrm{~min}$, the C.V. values will increase from 5.21 to $17.80 \%$, also homogeneity will increase from 6.86 to $16.60 \%$, while the mean will decrease from 20.25 to 19.20 . The coefficient of variation under $10 \%$ is considered excellent, of between $10-15 \%$ is good, of between $15-20 \%$ is fair.
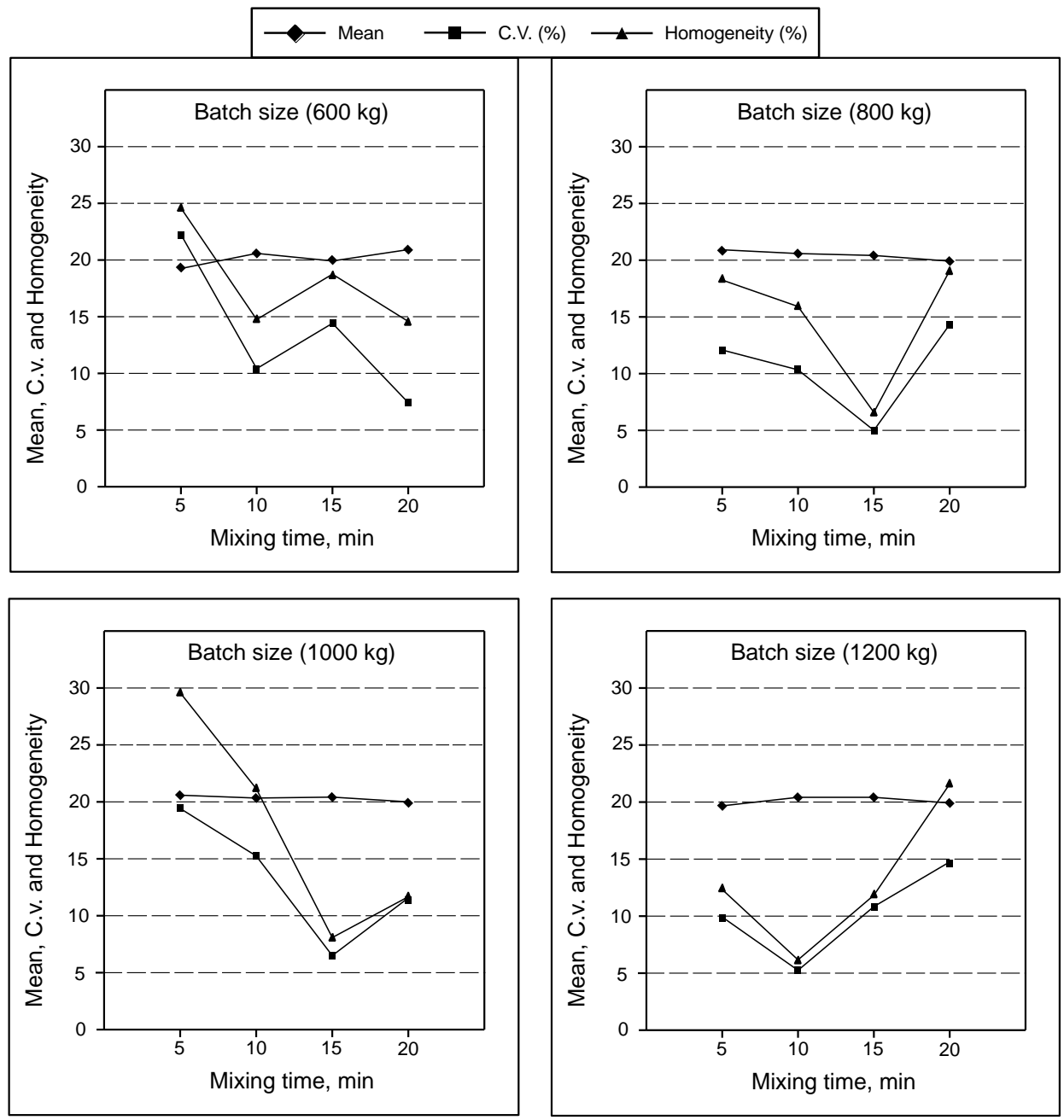

Fig. (1): Effect of mixing time and patch size on the mixer performance using calcium carbonate and corn gluten as a carrier material. 
While with value more than $20 \%$ is poor (as reported by Coates, 1992), so the mixing time of between 10 to $15 \mathrm{~min}$ is recommended because increasing mixing time more than 15 min leads to separate active materials from carrier materials, and active materials become granules particles, moreover mixing increase temperature and vitamin will be broken.

\subsubsection{Effect of mixing time and batch size on the mixer performance using calcium carbonate only as a carrier material:}

Concerning the effect of mixing time on mixer performance at batch size of $600 \mathrm{~kg}$, Results in Fig. (2) show that increasing mixing time from 5 to 10 min decreased both C.V. values from 11.19 to $3.24 \%$ and homogeneity from 18.82 to $4.47 \%$, while increased the mean from 20.46 to 20.51 . Any further increase in mixing time more than $10 \mathrm{~min}$ up to $20 \mathrm{~min}$, the C.V. values will increase from 3.24 to $7.89 \%$, also homogeneity will increase from 4.47 to $11.69 \%$, and also the mean will increase from 20.51 to 20.67 .
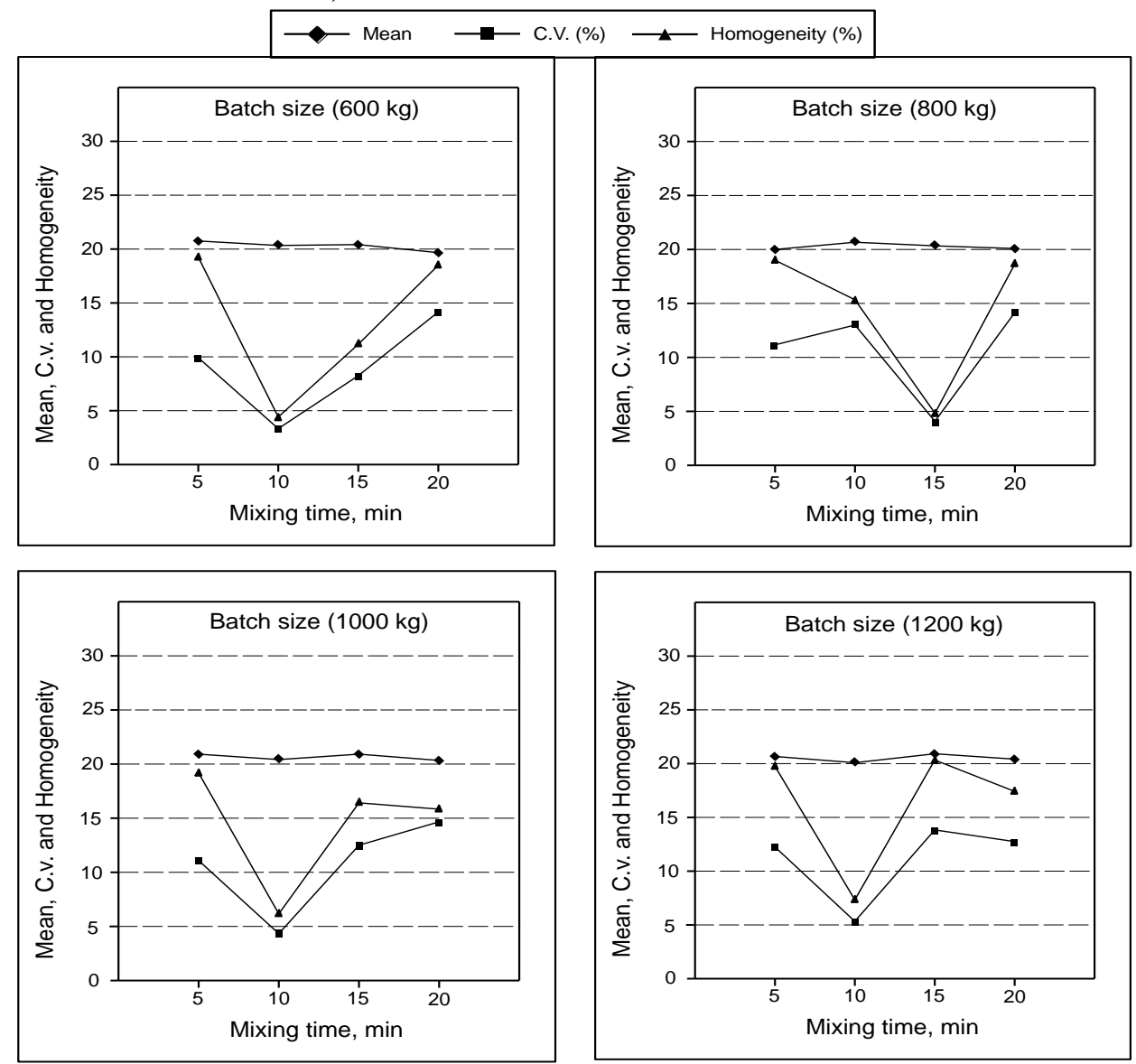

Fig.(2): Effect of mixing time and batch size on the mixer performance using calcium carbonate only as a carrier material. 
Relating to the effect of mixing time on mixer performance at batch size of $800 \mathrm{~kg}$, results show that increasing mixing time from 5 to 15 min decreased both C.V. values from 11.17 to $4.41 \%$ and homogeneity from 19.08 to 4.83 $\%$, and also increased the mean from 19.80 to 20.21. Any further increase in mixing time more than $15 \mathrm{~min}$ up to $20 \mathrm{~min}$, the C.V. values will increase from 4.41 to $14.06 \%$, also homogeneity will increase from 4.83 to $18.26 \%$, while the mean will decrease from 20.21 to 20.08 . Relating to the effect of mixing time on mixer performance at batch size of $1000 \mathrm{~kg}$, results show that increasing mixing time from 5 to 10 min decreased both C.V. values from 11.57 to $4.11 \%$ and homogeneity from 19.07 to $6.17 \%$, and also decreased the mean from 20.74 to 20.37 . Any further increase in mixing time more than $10 \mathrm{~min}$ up to $20 \mathrm{~min}$, the C.V. values will increase from 4.11 to $12.37 \%$, also homogeneity will increase from 6.17 to $16.49 \%$, and also the mean will increase from 20.37 to 20.88 . As to the effect of mixing time on mixer performance at batch size of $1200 \mathrm{~kg}$, results show that increasing mixing time from 5 to $10 \mathrm{~min}$ decreased both C.V. values from 11.85 to $5.43 \%$ and homogeneity from 20.06 to $7.70 \%$, and also decreased the mean from 21.00 to 20.16. Any further increase in mixing time more than $10 \mathrm{~min}$ up to $20 \mathrm{~min}$, the C.V. values will increase from 5.43 to $13.70 \%$, also homogeneity will increase from 7.70 to $20.97 \%$, and also the mean will increase from 20.16 to 21.28 .

\subsubsection{Effect of mixing time and batch size on the mixer performance using corn gluten only as a carrier material:}

Concerning the effect of mixing time on mixer performance at batch size of $600 \mathrm{~kg}$, Results in Fig. (3) show that increasing mixing time from 5 to 15 min decreased both C.V. values from 10.31 to $7.35 \%$ and homogeneity from 16.22 to $10.66 \%$ and also decreased the mean from 20.35 to 19.92 . Any further increase in mixing time more than $15 \mathrm{~min}$ up to $20 \mathrm{~min}$, the C.V. values will increase from 7.35 to $11.04 \%$, also homogeneity will increase from 10.66 to $19.41 \%$, and also the mean will increase from 19.92 to 20.33. Relating to the effect of mixing time on mixer performance at batch size of $800 \mathrm{~kg}$, results show that increasing mixing time from 5 to 10 min decreased both C.V. values from 11.79 to $7.08 \%$, and homogeneity from 18.86 to $10.95 \%$, and also the mean decreased from 20.07 to 19.99 . Any further increase in mixing time more than $10 \mathrm{~min}$ up to $20 \mathrm{~min}$, the C.V. 
values will increase from 7.08 to $12.38 \%$, also homogeneity will increase from 10.95 to $15.22 \%$, and also the mean will increase from 19.99 to 20.09. Regarding to the effect of mixing time on mixer performance at batch size of $1000 \mathrm{~kg}$, results show that increasing mixing time from 5 to $15 \mathrm{~min}$ decreased C.V. values from 12.51 to $6.26 \%$, and homogeneity from 16.42 to $9.05 \%$, and also decrease the mean from 20.30 to 20.18 .
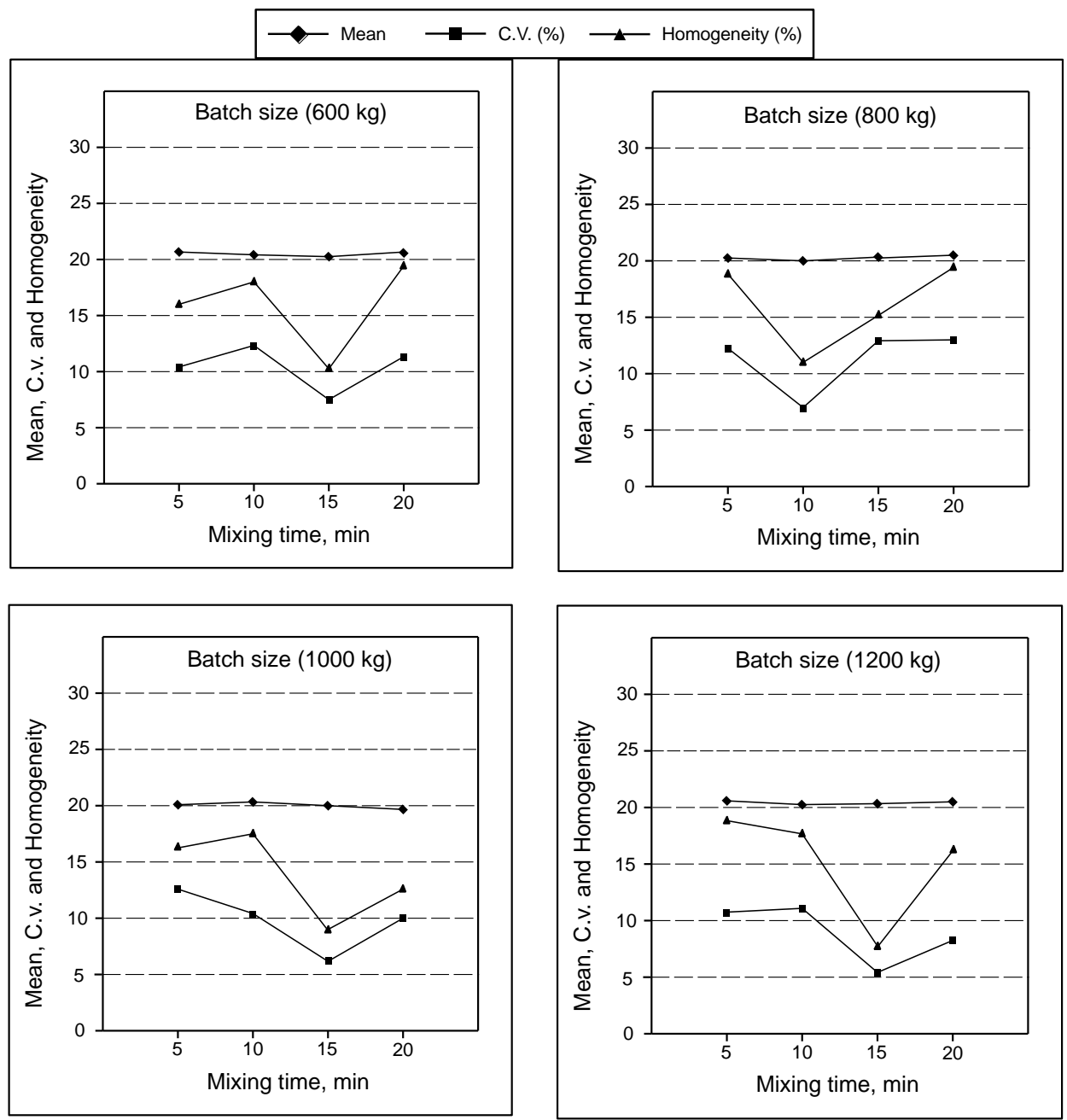

Fig.(3): Effect of mixing time and batch size on the mixer performance using corn gluten only as a carrier material. 
Any further increase in mixing time more than 15 min up to $20 \mathrm{~min}$, the C.V. values will increase from 6.26 to $9.88 \%$, also homogeneity will increase from 9.05 to $12.82 \%$, while the mean will decrease from 20.18 to 19.78. As to the effect of mixing time on mixer performance at batch size of $1200 \mathrm{~kg}$, results show that increasing mixing time from 5 to $15 \mathrm{~min}$ decreased C.V. values from 10.76 to $5.46 \%$, and homogeneity from 18.81 to $8.38 \%$, and also decreased the mean from 20.80 to 20.26 . Any further increase in mixing time more than $15 \mathrm{~min}$ up to $20 \mathrm{~min}$, the C.V. values will increase from 5.46 to $8.46 \%$, also homogeneity will increase from 8.38 to $16.22 \%$, and also the mean will increased from 20.26 to 20.63 .

\subsubsection{Effect of mixing time and batch size on energy requirements for (BUHLER) mixer:}

Fig. (4) show the effect of both mixing time and batch size on the energy requirements. Considering the effect of mixing time on the consumed energy, results show that increasing mixing time from 5 to 20 min the consumed energy increased from 4.17 to 16.67 , from 3.13 to 12.50 , from 2.50 to 10.00 , and from 2.08 to $8.33 \mathrm{~kW} . \mathrm{h} / \mathrm{Mg}$ at batch sizes of 600,800 , 1000 and $1200 \mathrm{~kg}$, respectively.
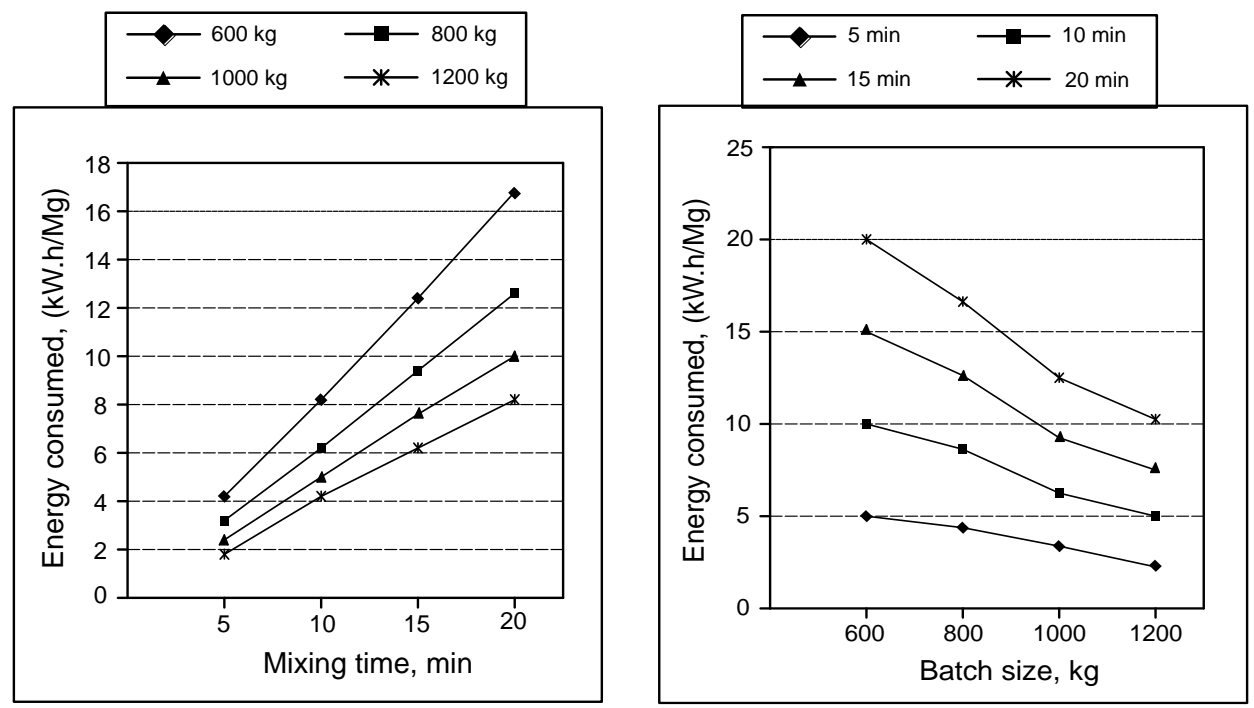

Fig. (4): Effect of mixing time and batch size on energy requirements using corn gluten and calcium carbonate as a carrier material. 
Relating to the effect of batch size on consumed energy, the obtained data show that increasing batch size from 600 to $1200 \mathrm{~kg}$ decreased the consumed energy from 4.17 to 2.08 , from 8.33 to 4.17 , from 12.50 to 6.25 , and from 16.67 to $8.33 \mathrm{~kW} . \mathrm{h} / \mathrm{Mg}$ at mixing time of $5,10,15$ and $20 \mathrm{~min}$, respectively. The decrease in consumed energy by increasing batch size is attributed to the smaller size of the vacuum in the mixer led to more efficient mixing.

\subsubsection{Effect of mixing time and batch size on mixing cost for BUHLER:}

Fig. (5) show the effect of both mixing time and batch size on mixing cost. Considering the effect of mixing time on mixing cost, results show that increasing mixing time from 5 to 20 minutes increased mixing cost from 56 to 222 , from 42 to 167, from 33 to 133, and from 28 to 111 L.E./Mg at batch sizes of $600,800,1000$ and $1200 \mathrm{~kg}$, respectively. Relating to the effect of batch size on mixing cost, the obtained data show increasing batch size from 600 to $1200 \mathrm{~kg}$ decreased mixing cost from 56 to 28 , from 111 to 56 , from 167 to 83, and from 222 to 111 L.E/Mg at mixing time of 5, 10, 15 and 20 minutes, respectively.
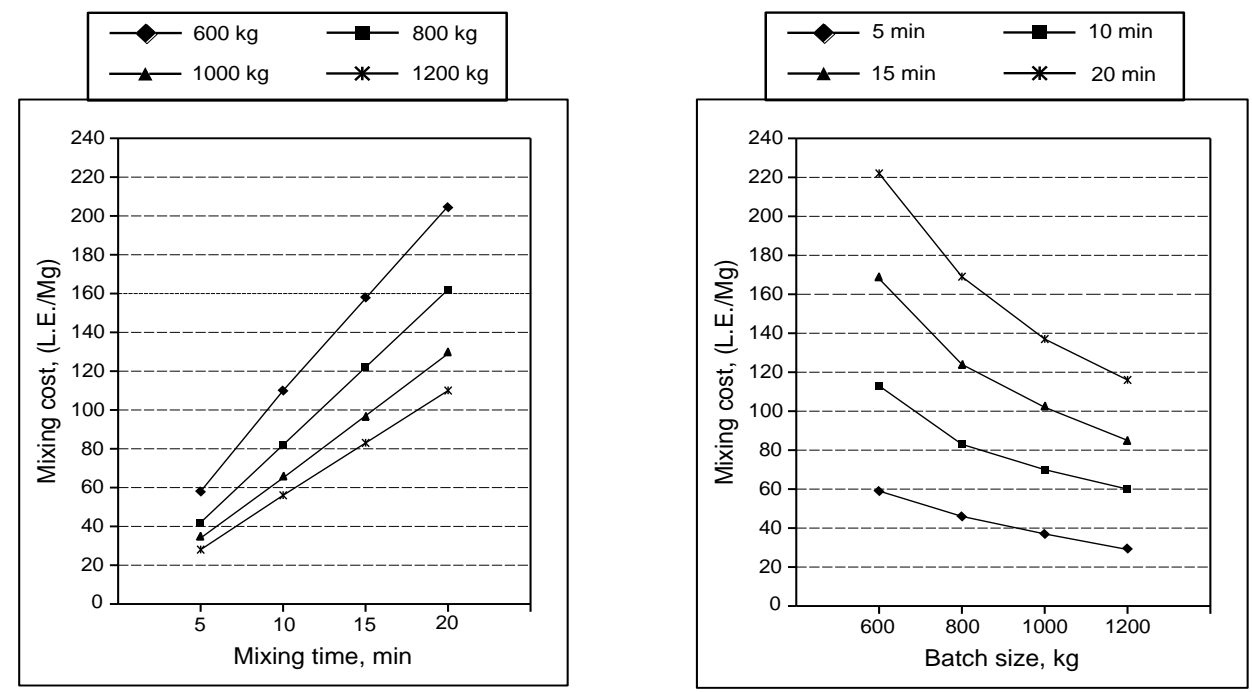

Fig.(5): Effect of mixing time and batch size on mixing cost using corn gluten and calcium carbonate as a carrier material.

Increasing mixing cost by increasing mixing time was due to increase more energy consumed to achieve for the suitable Mean, C.V. and 
homogeneity. While increasing batch size leads to decrease mixing cost due to increase mixer productivity which reduces the hourly mixing cost.

\subsection{RIBBON (Small mixer):}

\subsubsection{Effect of mixing time and batch size on the mixer performance using sucrose and Maltodextrin as a carrier material:}

Concerning the effect of mixing time on mixer performance during mixing of vitamin $\left(B_{1}\right)$ at batch size of $100 \mathrm{~kg}$, results in Fig. (6) show that increasing mixing time from 30 to $40 \mathrm{~min}$ decreased both C.V. values from 9.10 to $3.74 \%$ and homogeneity from 14.68 to $5.58 \%$, and also decreased the mean from 100.89 to 97.8 . Any further increase in mixing time more than $40 \mathrm{~min}$ up to $60 \mathrm{~min}$, the C.V. values will increase from 3.74 to $6.57 \%$, also homogeneity will increase from 5.58 to $11.39 \%$, and also the mean will increase from 97.80 to 100.60 .

Considering the effect of mixing time on mixer performance during mixing of vitamin $\left(\mathrm{B}_{1}\right)$ at batch size of $150 \mathrm{~kg}$, results show that increasing mixing time from 30 to 40 min decreased both C.V. values from 10.02 to $3.31 \%$ and homogeneity from 11.34 to $4.63 \%$, and also decrease the mean from 98.69 to 97.62 . Any further increase in mixing time more than 40 min up to $60 \mathrm{~min}$, the C.V. values will increase from 3.31 to $8.53 \%$, also homogeneity will increase from 4.63 to $9.03 \%$, and also the mean will increase from 98.697 to 97.17 . Concerning the effect of mixing time on mixer performance during mixing of vitamin $\left(B_{1}\right)$ at batch size of $200 \mathrm{~kg}$, results in Fig. (6) show that increasing mixing time from 30 to $50 \mathrm{~min}$ decreased both C.V. values from 5.52 to $4.92 \%$ and homogeneity from 8.69 to $8.75 \%$, and also decreased the mean from 99.92 to 96.73 .

Any further increase in mixing time more than $40 \mathrm{~min}$ up to $60 \mathrm{~min}$, the C.V. values will increase from 4.92 to $9.10 \%$, also homogeneity will increase from 8.75 to $14.71 \%$, while the mean will decrease from 96.73 to 97.24. Relating to the effect of mixing time on mixer performance during mixing of vitamin $\left(B_{1}\right)$ at batch size of $250 \mathrm{~kg}$, results show that increasing mixing time from 30 to $60 \mathrm{~min}$ decreased both C.V. values from 9.14 to $3.66 \%$ and homogeneity from 17.16 to $5.42 \%$, and also decreased the mean from 97.48 to 97.41 . 

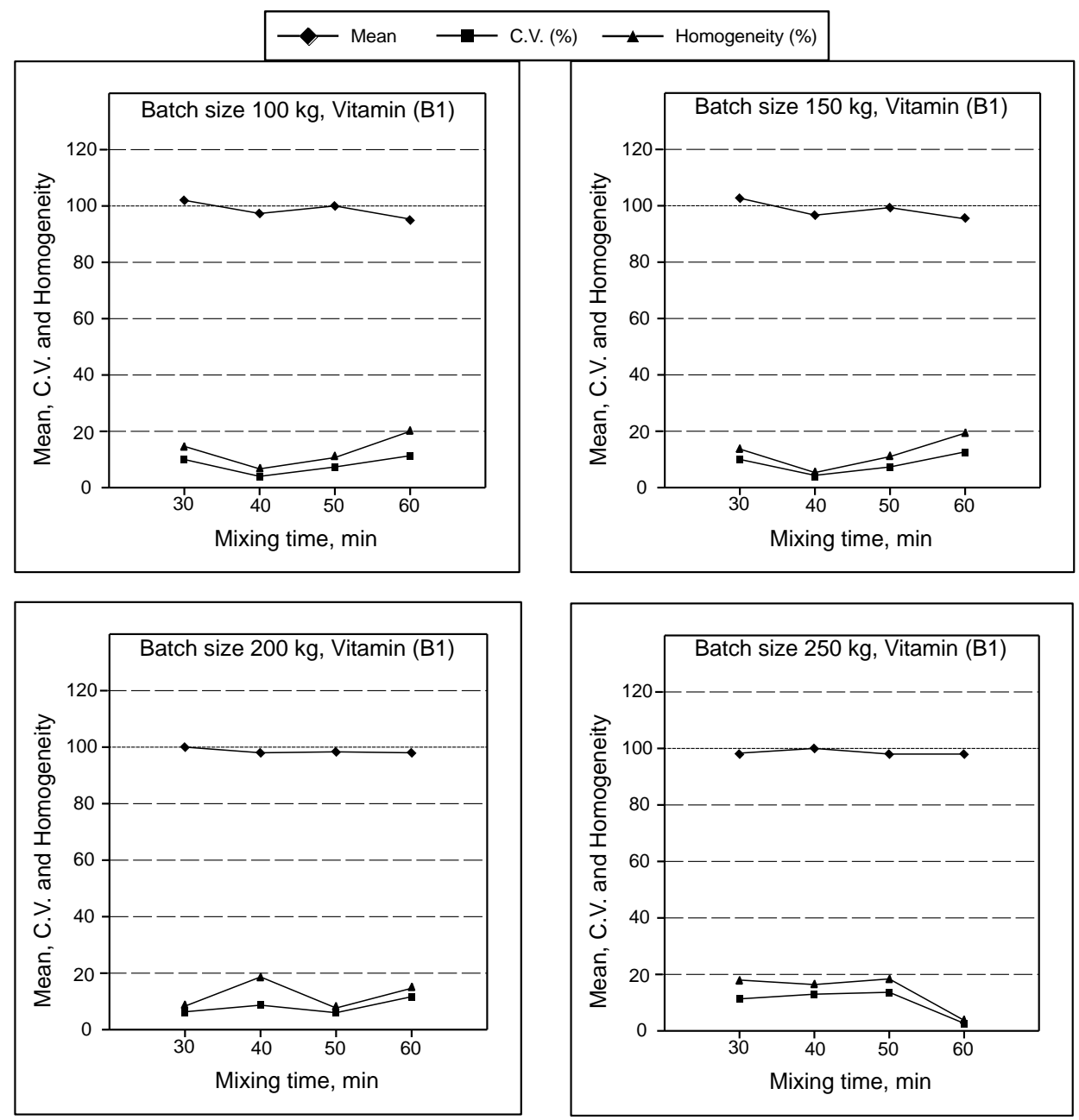

Fig.(6): Effect of mixing time at batch size on the mixer performance using sucrose and Maltodextrin as a carrier material.

\subsubsection{Effect of mixing time and batch size on the mixer performance using Maltodextrin only as a carrier material:}

Concerning the effect of mixing time on mixer performance during mixing vitamin $\left(B_{1}\right)$ at batch size of $100 \mathrm{~kg}$, results in Fig. (7) show that increasing mixing time from 30 to 40 min decreased both C.V. values from 10.92 to $2.90 \%$ and homogeneity from 8.54 to $4.12 \%$, while increased the mean from 96.71 to 97.47 . Any further increase in mixing time more than $40 \mathrm{~min}$ up to $60 \mathrm{~min}$, the C.V. values will increase from 2.90 to $10.81 \%$, also homogeneity will increase from 4.12 to $10.79 \%$, and also the mean will 
increase from 97.47 to 98.88 . Concerning the effect of mixing time on mixer performance during mixing of vitamin $\left(\mathrm{B}_{1}\right)$ at batch size of $150 \mathrm{~kg}$, results show that increasing mixing time from 30 to 40 min decreased both C.V. values from 8.68 to $2.41 \%$ and homogeneity from 8.70 to $3.46 \%$, while increased the mean from 96.54 to 97.63 . Any further increase in mixing time more than $40 \mathrm{~min}$ up to $60 \mathrm{~min}$, the C.V. values will increase from 2.41 to $8.72 \%$, also homogeneity will increase from 3.46 to $9.04 \%$, while the mean will decrease from 97.63 to 97.25 .
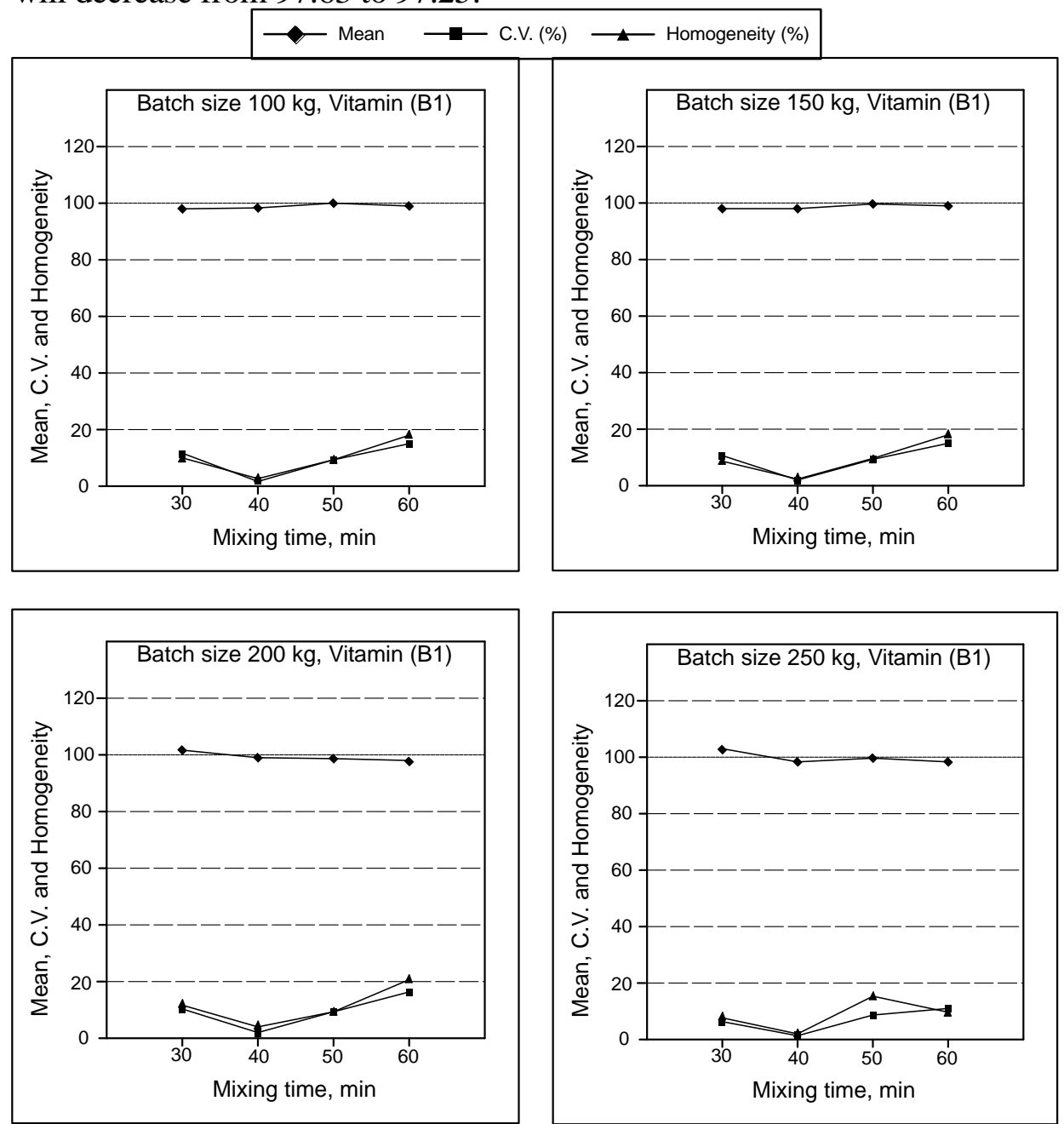

Fig.(7): Effect of mixing time and batch size on the mixer performance using Maltodextrin only as a carrier material. 
Concerning the effect of mixing time on mixer performance during mixing of vitamin $\left(B_{1}\right)$ at batch size of $200 \mathrm{~kg}$, results show that increasing mixing time from 30 to 40 min decreased both C.V. values from 9.02 to $3.64 \%$ and homogeneity from 12.37 to $6.88 \%$, and also decreased the mean from 101.22 to 97.98. Any further increase in mixing time more than $40 \mathrm{~min}$ up to $60 \mathrm{~min}$, the C.V. values will increase from 3.64 to $10.22 \%$, also homogeneity will increase from 6.88 to $9.37 \%$, while the mean will decrease from 97.98 to 98.46 . Relating to the effect of mixing time on mixer performance during mixing of vitamin $\left(B_{1}\right)$ at batch size of $250 \mathrm{~kg}$, results show that increasing mixing time from 30 to 40 min decreased both C.V. values from 7.25 to $2.31 \%$ and homogeneity from 10.13 to $3.66 \%$, and also decreased the mean from 102.77 to 97.68 . Any further increase in mixing time more than $40 \mathrm{~min}$ up to $60 \mathrm{~min}$, the C.V. values will increase from 2.31 to $8.53 \%$, also homogeneity will increase from 3.66 to $16.54 \%$, while the mean will decrease from 97.68 to 97.04 .

\subsubsection{Effect of mixing time and batch size on the mixer performance using sucrose only as a carrier material:}

Concerning the effect of mixing time on mixer performance during mixing vitamin $\left(B_{1}\right)$ at batch size of $100 \mathrm{~kg}$, results Fig.(8) show that increasing mixing time from 30 to $50 \mathrm{~min}$ decreased both C.V. values from 10.14 to $3.00 \%$ and homogeneity from 10.30 to $5.86 \%$, and also increased the mean from 98.22 to 97.83 . Any further increase in mixing time more than $40 \mathrm{~min}$ up to $60 \mathrm{~min}$, the C.V. values will increase from 3.00 to $10.99 \%$, also homogeneity will increase from 5.86 to $18.46 \%$, and also the mean will decrease from 97.83 to 97.25 . Concerning the effect of mixing time on mixer performance during mixing vitamin $\left(B_{1}\right)$ at batch size of $150 \mathrm{~kg}$, results in Fig.(10) show that increasing mixing time from 30 to $40 \mathrm{~min}$ decreased both C.V. values from 10.82 to $2.51 \%$ and homogeneity from 12.30 to $4.51 \%$, and also decreased the mean from 101.23 to 99.82 . Any further increase in mixing time more than $40 \mathrm{~min}$ up to $60 \mathrm{~min}$, the C.V. values will increase from 2.51 to $10.01 \%$, also homogeneity will increase from 4.51 to $12.44 \%$, and also the mean will increase from 99.82 to 101.02 . Concerning the effect of mixing time on mixer performance during mixing of vitamin $\left(B_{1}\right)$ at batch size of $200 \mathrm{~kg}$, results show that increasing mixing time from 30 to 40 min decreased both C.V. values from 10.84 to $4.59 \%$ 
and homogeneity from 11.42 to $5.63 \%$, and also increased the mean from 98.12 to 98.27 . Concerning the effect of mixing time on mixer performance during mixing of vitamin $\left(\mathrm{B}_{1}\right)$ at batch size of $250 \mathrm{~kg}$, results show that increasing mixing time from 30 to $60 \mathrm{~min}$ decreased both C.V. values from 9.22 to $4.08 \%$ and homogeneity from 13.23 to $5.80 \%$, and also decreased the mean from 102.33 to 98.04 .
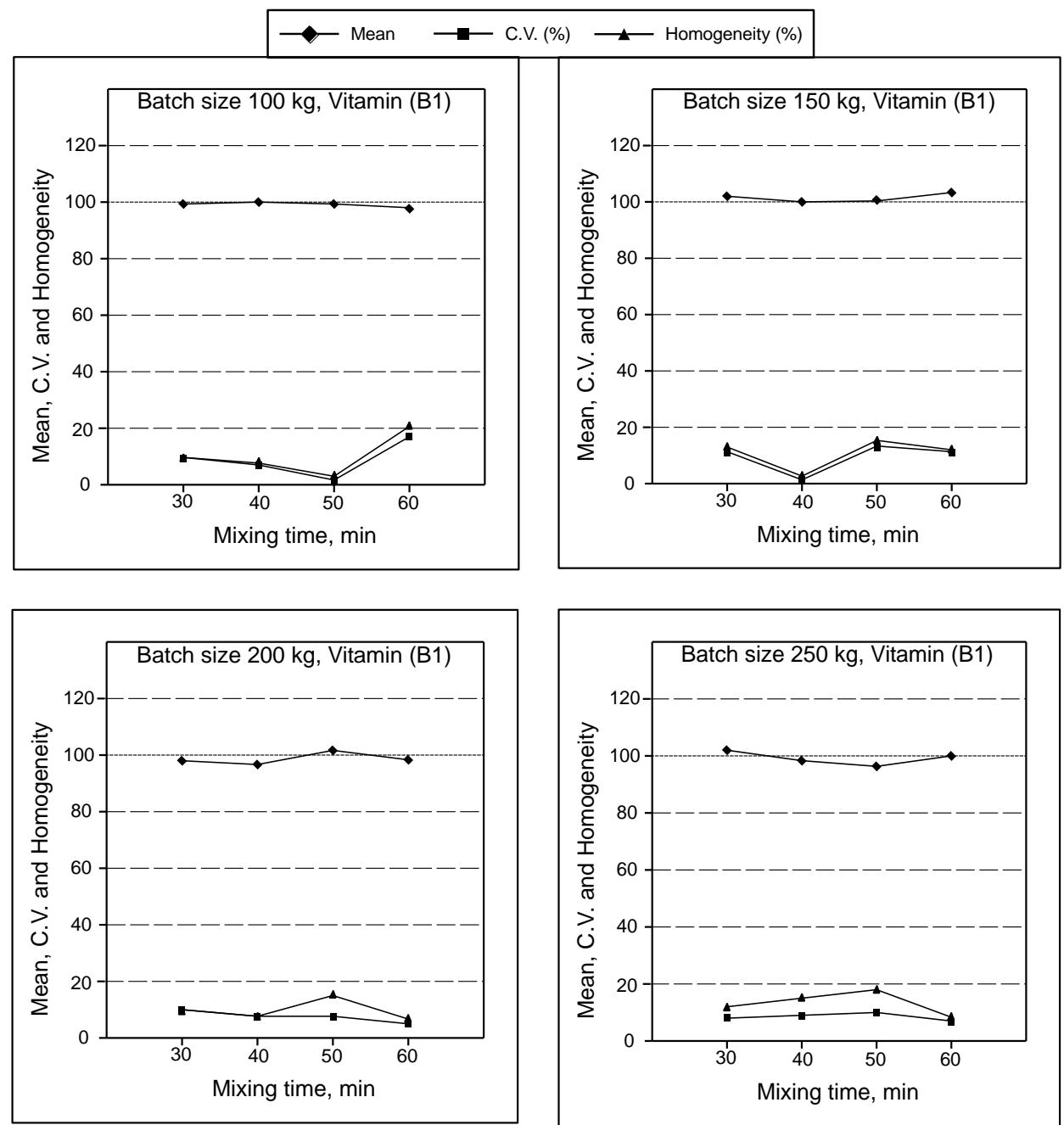

Fig.(8): Effect of mixing time and batch size on the mixer performance using sucrose only as a carrier material. 


\subsubsection{Effect of mixing time and batch size on energy requirements using sucrose and Maltodextrin as carrier material:}

Fig. (9) show the effect of both mixing time and batch size on the energy requirements. Considering the effect of mixing time on the energy requirements, results show that increasing mixing time from 30 to 60 minutes increased energy requirements from 55 to 110 , from 37 to 73 , from 28 to 55, and from 22 to $44 \mathrm{~kW} . \mathrm{h} / \mathrm{Mg}$ at batch sizes of 100, 150, 200 and $250 \mathrm{~kg}$, respectively. Relating to the effect of batch size on energy requirements, the obtained data show that increasing batch size from 100 to $250 \mathrm{~kg}$, decreased energy requirements from 55 to 22 , from 73 to 29 , from 92 to 37 , and from 110 to $44 \mathrm{~kW} . \mathrm{h} / \mathrm{Mg}$ at mixing times of $30,40,50$ and 60 minutes, respectively.
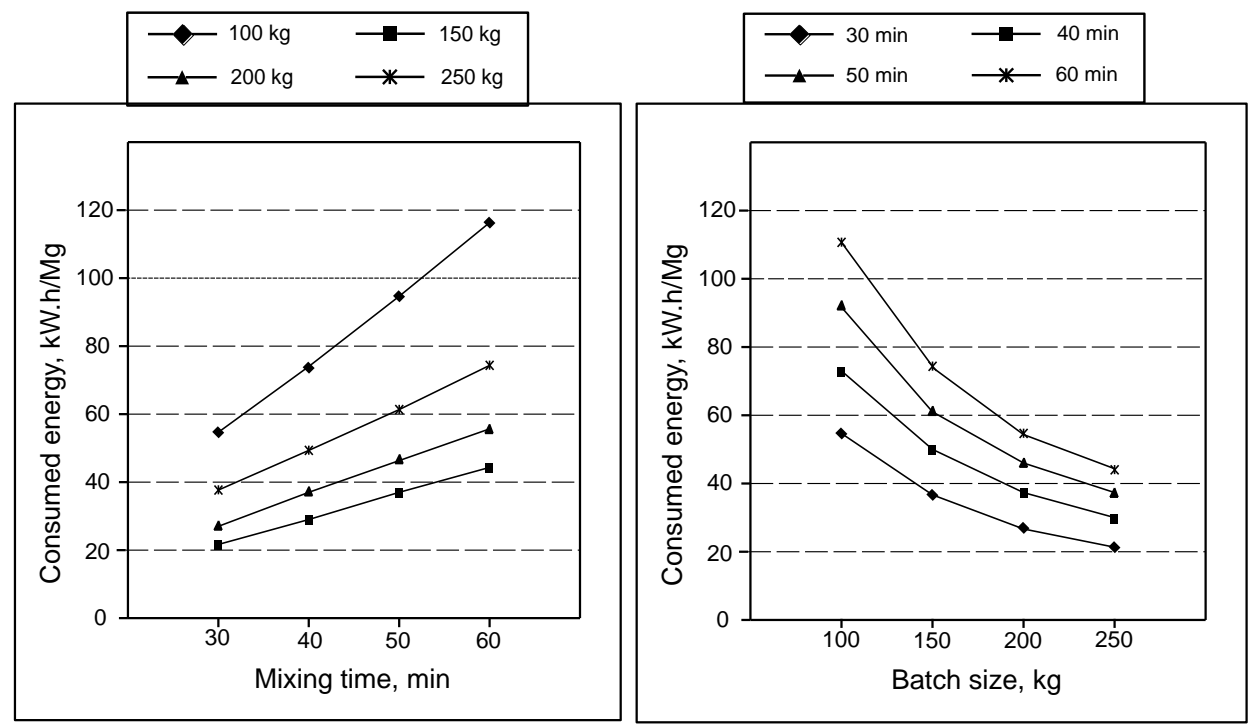

Fig. (9): Effect of mixing time and batch size on energy requirements using sucrose and Maltodextrin as carrier material.

3.2.5. Effect of mixing time and batch size on mixing cost using sucrose and maltodextrin as carrier material: 
Fig. (10) show the effect of both mixing time and batch size on mixing cost. Considering the effect of mixing time on mixing cost, results show that increasing mixing time from 30 to 60 minutes increased mixing cost from 250 to 500 , from 167 to 333 , from 125 to 250 and from 100 to 200 L.E. $/ \mathrm{Mg}$ at batch sizes of $100,150,200$ and $250 \mathrm{~kg}$, respectively. Relating to the effect of batch size on mixing cost, the obtained data show that increasing batch size from 100 to $250 \mathrm{~kg}$ decreased mixing cost from 250 to 100, from 333 to 133 , from 417 to 167 and from 500 to 200 L.E./Mg at mixing times of 30, 40, 50 and 60 minutes, respectively. Increasing mixing cost by increasing mixing time was due to increase more energy consumed to achieve for the suitable Mean, C.V. and homogeneity. While increasing batch size leads to decrease mixing cost due to increase mixer productivity which reduces the hourly mixing cost.
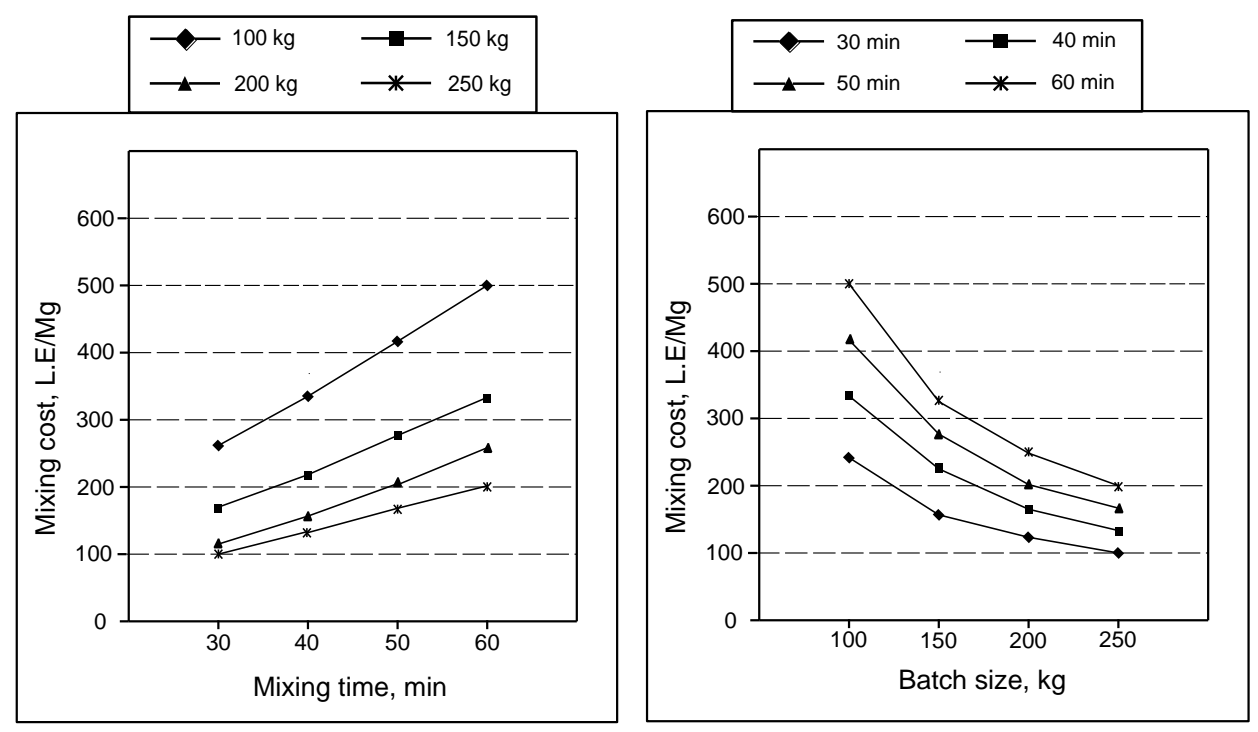

Fig. (10): Effect of mixing Time and batch size on mixing cost using sucrose and Maltodextrin as carrier material. 


\section{CONCLUSION}

- The big mixer (BUHLER) is recommended to be used for producing feed additives for batch size 1000 and $1200 \mathrm{~kg}$ because of its minimum consumed energy and mixing costs at mixing time of 10 min using carrier material of calcium carbonate and corn gluten with ratio of $3: 1$.

- The small mixer (RIBBON) is recommended to be used for producing feed additives for batch size of between 200 and $250 \mathrm{~kg}$ because of its minimum consumed energy and mixing costs at mixing time of $60 \mathrm{~min}$ using carrier material of sucrose and Maltodextrin with ratio of $1: 1$.

\section{REFERENCES}

ASAE (1997a): Cubes, Pellets, an Crumbles-Definitions and methods for determining density, durability, and moisture. Standards 1997. Am. Soc. Agric. Eng., St. Joseph, MI.

ASAE (1997b): Method of determining and expressing fineness of feed materials by Sieving. Standards 1997. Am. Soc. Agric. Eng., St. Joseph, MI.

Avik, S. and C. R. Wassgrena (2009): Simulation of a continuous granular mixer: Effect of operating conditions on flow and mixing. Chemical Engineering Science 64: 2672 - 2682.

Clark, P. M. and K. C. Behnke (2006): Effects of pelleting protein concentrate pellets on feed mill throughput and electrical efficiency. Poult. Sci. 83 (Suppl. 1):170(Abst.).

Coates, P. M. and K. Tanaka (1992): New developments in fatty acid oxidation. New York: willey-Liss.

Dirksen, G. U; H. G. Liebich and E. Mayer (1980): Feed manufacturing problems-incomplete mixing and segregation. C-555 Revised. KSU Cooperative Extension Service. Manhattan, KS. 
Portillo, P. M; M. G. Ierapetritou and F. J. Muzzio (2007): Characterization of continuous convective powder mixing processes. Powder Technology 182: 368-378.

Traylor, S. L. (1997): Effects of feed processing on diet characteristics and animal performance. Masters Thesis, Kansas State University, Manhattan, KS.

\section{الملخـص العـربي}

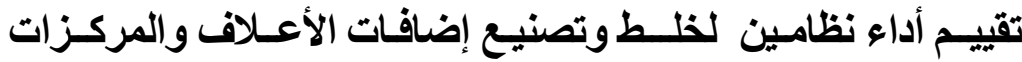

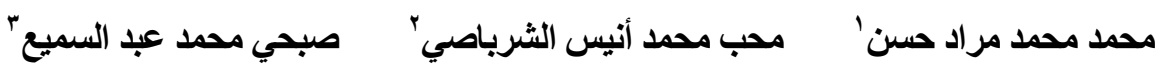

أجريت هذه الدراسة بمصنع لإنتاج إضافات الأعلاف و المركز ات بمدينه العبور - محافظة القليو بية

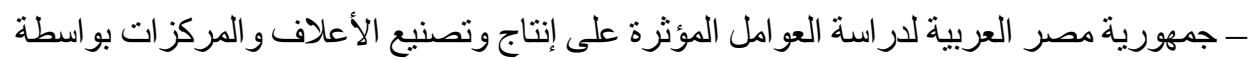

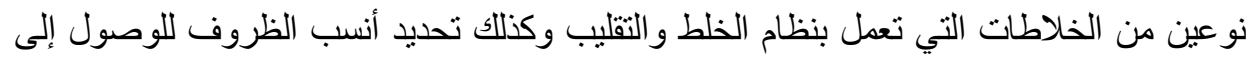

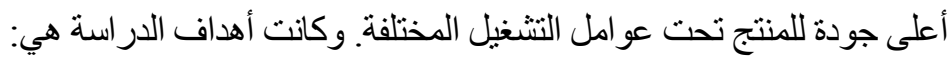

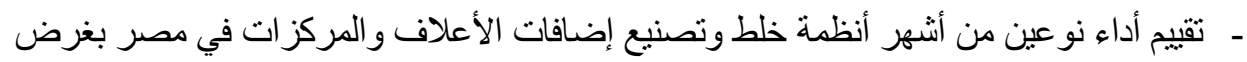
إنتاج إضافات علف ومركزات ذات جودة عالية لتحقيق الهوف المنشود منها في تحسين إنتاج

$$
\text { الثروة الحيو انية. }
$$

- تحديد أفضل عو امل التشغيل للحصول على أعلى كفاءة تثغيل لأنظمة الخلط و التقليب المستخدمة. - حساب الطاقة اللازمة لتشغيل نو عبن من أنظمة الخلط. - تقبيم أداء نو عين من أنظمة خلط وتصنيع إضافات الأعلاف و المركز ات اقتصادياً. وقد تم إجراء مجموعتين من التجارب كالتالي:-

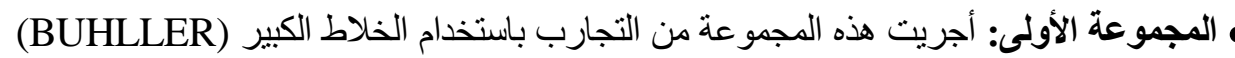

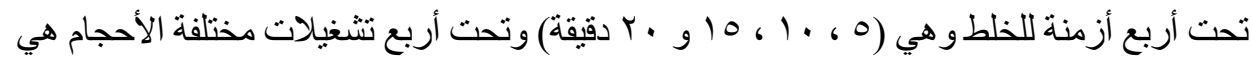

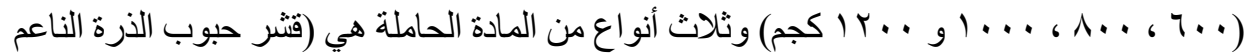

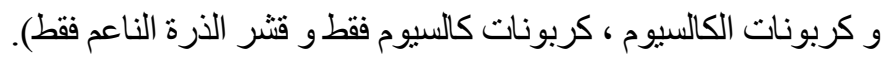

' أستاذ ـ قسم الهندسة الزراعية _ كلية الزراعة - جامعة الزقازيق - مصر.

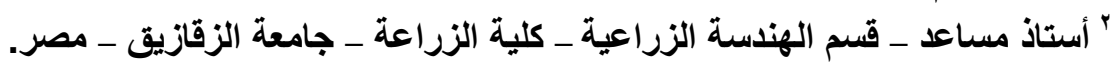

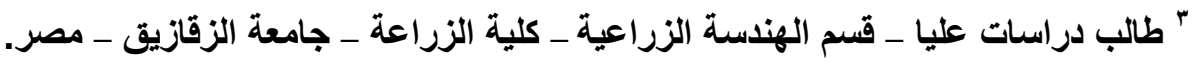




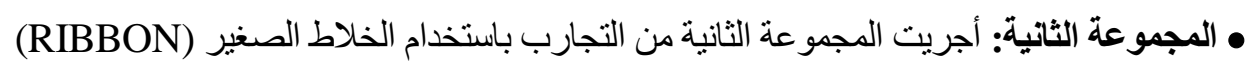

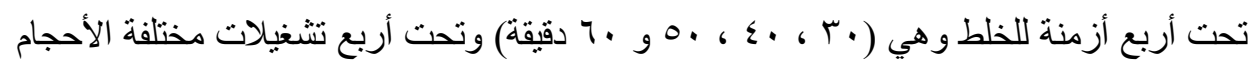

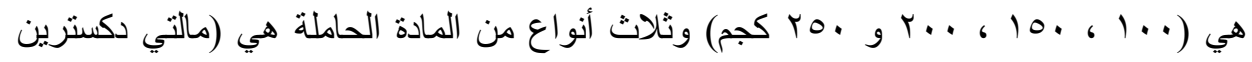

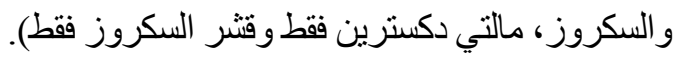

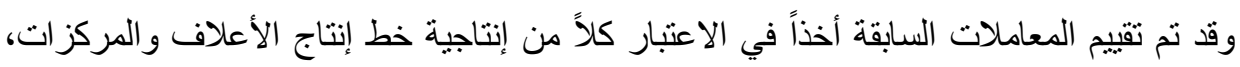

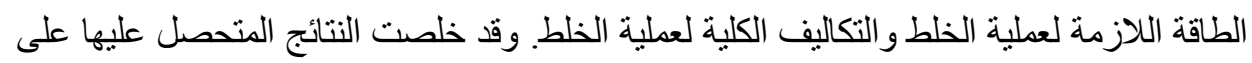
ما يلي:

- استخدام الخلاط الكبير (BUHLLER) في إنتاج إضافات الأعلاف عندما يكون حجم التشغيلة

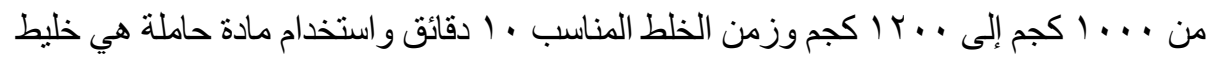

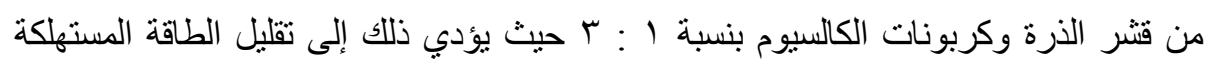
وكذلك التكاليف الكلية لعملية الخلط.

- استخدام الخلاط الصغير (RIBBON) في إتتاج إضافات الأعلاف عندما يكون حجم التشغيلة

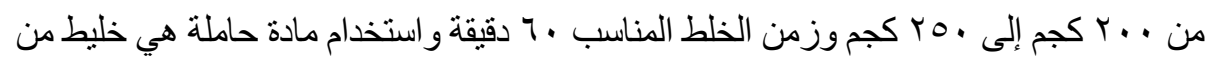

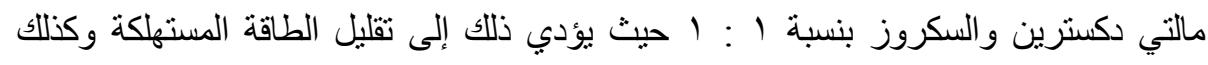
التكاليف الكلية لعملية الخلط. 